\title{
BMJ Open Why do trainees leave hospital-based specialty training? A nationwide survey study investigating factors involved in attrition and subsequent career choices in the Netherlands
}

Jacqueline Bustraan, ${ }^{1}$ Kirsten Dijkhuizen, ${ }^{1,2}$ Sophie Velthuis, ${ }^{1}$ Rachel van der Post ${ }^{3}$ Erik Driessen, ${ }^{4}$ Jan M M van Lith, ${ }^{2}$ Arnout Jan de Beaufort ${ }^{1}$

To cite: Bustraan J,

Dijkhuizen K, Velthuis S, et al. Why do trainees leave hospital-based specialty training? A nationwide survey study investigating factors involved in attrition and subsequent career choices in the Netherlands. BMJ Open 2019;9:e028631. doi:10.1136/ bmjopen-2018-028631

- Prepublication history and additional material for this paper are available online. To view these files, please visit the journal online (http://dx. doi org/10.1136/bmjopen-2018028631).

$\mathrm{JB}$ and $\mathrm{KD}$ contributed equally.

Received 18 December 2018 Revised 20 March 2019 Accepted 23 April 2019
Check for updates

(C) Author(s) (or their employer(s)) 2019. Re-use permitted under CC BY-NC. No commercial re-use. See rights and permissions. Published by BMJ.

For numbered affiliations see end of article.

Correspondence to Dr Kirsten Dijkhuizen; k.dijkhuizen@lumc.nl

\section{ABSTRACT}

Objective To gain insight into factors involved in attrition from hospital-based medical specialty training and future career plans of trainees who prematurely left their specialty training programme.

Design Nationwide online survey study.

Setting Postgraduate education of all hospital-based specialties in the Netherlands.

Participants 174 trainees who prematurely left hospitalbased medical specialty training between January 2014 and September 2017.

Main outcome measures Factors involved in trainees' decisions to leave specialty training and their subsequent career plans.

Results The response rate was $38 \%$. Of the responders, $25 \%$ left their programme in the first training year, $50 \%$ in year 2-3 and $25 \%$ in year $4-6$. The most frequently reported factors involved in attrition were: work-life balance, job content, workload and specialty culture. Of the leaving trainees, $66 \%$ switched to another specialty training programme, of whom two-thirds chose a nonhospital-based training programme. Twelve per cent continued their career in a non-clinical role and the remainder had no specific plans yet.

Conclusions This study provides insight in factors involved in attrition and in future career paths. Based on our findings, possible interventions to reduce attrition are: (1) enable candidates to develop a realistic view on job characteristics and demands, prior to application; (2) provide individual guidance during specialty training, with emphasis on work-life balance and fit with specialty.

\section{INTRODUCTION}

Attrition of medical trainees is a worldwide concern that 'comes at a high cost'. For society, attrition may imply the loss of an almost qualified member of the medical workforce and thereby affects healthcare. ${ }^{2}$ At the programme level, the remaining group of trainees and their training programme director (TPD) may face a negative effect on programme morale ${ }^{3}$ and practical
Strengths and limitations of this study

- This is the first nationwide study to investigate factors involved in attrition across all hospital-based specialties over an extended period of time $(3,5$ years).

- Our study provides insight in factors involved in trainee attrition and in their subsequent career ambitions.

- Limitations of the study are the limited response rate and the self-reporting nature, the latter might contribute to psychological bias, such as cognitive dissonance and internal and external attribution.

consequences such as scheduling and replacement issues. The impact for trainees depends on the reasons underlying the decision to leave: a trainee who invested a lot to get into a competitive training programme but is dismissed may end up with uncertain prospects, whereas a trainee who decided to switch to another specialty with a better fit has a positive impact at all levels. Insight into factors involved in attrition is limited, and few studies address future careers of trainees who left a specialty training programme. ${ }^{45}$

Most studies on attrition provide valuable yet limited evidence by (1) focusing on trainee attrition within one specialty, ${ }^{56}$ in particular general surgery $^{7-9}$ and (2) investigating single factors, that is, gender, ${ }^{4}$ risk tolerance, ${ }^{10}$ duty hours or lifestyle issues. ${ }^{8}{ }^{11-13}$ Factors associated with attrition are frequently reported by TPDs and not by the trainees involved, which might give a unilateral impression. ${ }^{9}$ Bongiovanni et al identified four themes to be at stake in attrition: a breach of an informal contract when clinical duties are prioritised over education, a culture lacking safe space to share personal and programmatic concerns, 
scarcity of role models demonstrating better work-life balance and loss of commitment after negative interactions with authority.

Studies focusing on demographics or personality characteristics as predictors for attrition provide inconclusive evidence as some show an association, ${ }^{14} 15$ whereas others do not. ${ }^{9}{ }^{16}$ Studies on the effect of duty hours also show different outcomes. ${ }^{11}{ }^{13}$ Moreover, attrition and factors potentially involved in attrition, for example, well-being, lifestyle, are not uniformly defined ${ }^{17} 18$ and comparison of studies is further hindered by different study designs. ${ }^{19}{ }^{20}$ Most studies on trainee attrition stem from the USA and Canada. Given the importance of context in workplace-based learning, ${ }^{21}{ }^{22}$ findings from these studies may not apply to other contexts of postgraduate training, for example, Western Europe, as matching systems and study debt-related issues may differ.

Few studies address the career paths of trainees leaving specialty training. ${ }^{421323}$ These studies show that the vast majority of leaving trainees switches to another, mostly hospital-based, training programme. Surgical trainees pursue their career in a diversity of hospital-based specialties, most frequently anaesthesiology and radiology. ${ }^{4} 1213$ The pursuit of a non-medical career is rare $(<5 \%)$.

We conducted a survey study among all medical trainees leaving hospital-based specialty training in the Netherlands to identify factors involved in the decision to leave specialty training and to gain insight into trainees' future career choices. Insight into these factors and choices could lead to a better understanding of the impact of attrition and facilitate the development of interventions to limit avoidable attrition.

\section{METHODS \\ Design}

We performed a nationwide online survey study among trainees who prematurely left their specialty training in the Netherlands. We included trainees from all 27 hospital-based medical specialties. Trainees from non-hospital-based programmes, for example, general practice, public and occupational health, were excluded as training contexts and regulations differed from hospital-based training programmes.

\section{Setting}

Hospital-based specialty training programmes in the Netherlands are competency-based according to the CanMEDS-framework and last between 3 and 6 years. ${ }^{24}$ Every year around 1350 new trainees commence specialty training. Average societal costs per trainee are $€ 125000$ annually. Specialty training positions are scarce and subject to severe competition. As a consequence, junior doctors face a delay of 3years on average between graduation and start of specialty training. ${ }^{25}$ Between graduation and specialty training they work as $\mathrm{PhD}$ candidate or as 'doctor not-in-training' (DNIT). ${ }^{26}$ DNIT positions are usually in the specialty of first choice and, unlike the British foundation years, not obligatory. In the first year of specialty training, trainee and TPD have quarterly progress meetings. At the end of this year, a 'go or no-go' decision is made. Afterwards progress meetings take place from twice in the second year to once in the remaining programme years.

The Dutch National Registration Committee of Medical Specialties (in Dutch: RGS) registers all medical trainees. The overall attrition rate from hospital-based specialties in the Netherlands is $11 \%$ (range between specialties 2.2\% and $24.3 \%$, see online supplementary appendix 1 ), with no gender difference. ${ }^{27}$ Current regulations do not allow to fill vacancies resulting from attrition after the first training year.

\section{Recruitment and data collection}

As part of the standard procedure in attrition, the RGS sends a confirmation email to each trainee who left training. During the study period, this confirmation email included information on our study and a link to the online questionnaire. Trainees consented to participate by clicking on the link after having read the information. Participation was voluntary and anonymous. The research team did not have any contact information of the leaving trainees and therefore could not send reminders. Data were collected from 1 January 2014 until 1 September 2017.

\section{Patient and public involvement}

Our study did not involve patients or public since our study focused on medical specialist training and not on healthcare.

\section{Development of questionnaire}

Our questionnaire covered the following topics: demographics (age, sex, training year, specialty), personal characteristics (previous DNIT-ship in the same specialty, decision to leave), factors involved in the trainee's decision to leave and future career intentions. The questionnaire was based on three sources: a literature review (see online supplementary appendix 2 for search terms), three interviews with trainees who prematurely left specialty training and the Job Demands Resources Model. ${ }^{28}$ We chose to provide trainees with a preset list of factors instead of open questions, in favour of user-friendliness and response rate. Trainees could select factors which played a role in their decision to leave from the preset list in a binary way. Respondents could add 'explanatory comments' or 'other factors' in narrative comment boxes to report relevant information or factors not provided in the preset list. After piloting the first version with three trainees and two TPDs, minor adjustments on clarity and formulation were made.

\section{Data analysis}

Descriptive statistics on frequencies of baseline characteristics were calculated. Differences between subgroups were calculated using Pearson's $\mathrm{X}^{2}$ test or Fisher's exact test. An $\alpha$ of 0.05 was considered significant. Subgroup analyses were performed based on gender, age, training year at the time of attrition, previous employment as a DNIT in the same specialty and specialty type (surgical vs medical vs other). Specialties were categorised according to the NHS specialties ${ }^{29}$ (see footnote table 1). Descriptive 
Table 1A Baseline characteristics of respondents $(n=174)$ and reference group $(n=460)$

\begin{tabular}{lcl}
\hline Characteristic & $\begin{array}{l}\text { Respondents } \\
\text { n (\%) }\end{array}$ & $\begin{array}{l}\text { Reference group* } \\
\mathbf{n}(\%)\end{array}$ \\
\hline $\begin{array}{l}\text { Sex and age } \\
\text { Female }\end{array}$ & $92(80 \%)$ & $317(69 \%)$ \\
Male & $23(20 \%)$ & $143(31 \%)$ \\
\hline Median age (range) & $31.0(24-46)$ & $32.5(24-58)$ \\
Training year at time of & & \\
attrition (TY) & & \\
\hline 1 & $46(26.4 \%)$ & (data not available) \\
\hline 2 & $45(25.9 \%)$ & \\
3 & $42(24.1 \%)$ & \\
4 & $21(12.1 \%)$ & \\
5 & $16(9.2 \%)$ & \\
6 & $4(2.3 \%)$ \\
\hline
\end{tabular}

Past employment as

DNIT within same

specialty:

\begin{tabular}{|c|c|c|}
\hline Yes & $105(60.3 \%)$ & (data not available) \\
\hline No & 69 (39.7\%) & \\
\hline \multicolumn{3}{|c|}{$\begin{array}{l}\text { Decision for } \\
\text { discontinuation taken by: }\end{array}$} \\
\hline Trainee & $144(82.8 \%)$ & (data not available) \\
\hline $\begin{array}{l}\text { Trainee and training } \\
\text { programme director }\end{array}$ & $22(12.6 \%)$ & \\
\hline $\begin{array}{l}\text { Training programme } \\
\text { director }\end{array}$ & $8(4.6 \%)$ & \\
\hline
\end{tabular}

${ }^{*}$ Our sample of respondents is a subset of the total reference group. Data on the reference group were obtained from the Registration Committee of Medical Specialties. Data on TY, previous DNIT-ship and decision of non-responders are not available. Published with permission.

DNIT, doctor not-in-training.

statistics and subgroup analyses were calculated for valid cases. Missing data were not replaced with substituted values.

Analysis of narrative data on 'other factors' and 'explanatory comments' were compared with the list of preset factors. Analysis provided both additional insight into what the 'factor' meant to the participants and revealed new factors. We classified the latter into three additional categories in agreement with three researchers $(\mathrm{KD}, \mathrm{JB}$, $\mathrm{AJdB})$.

\section{RESULTS}

\section{Respondents' characteristics}

In our study period, 460 trainees prematurely left specialty training, 174 of which completed our online questionnaire (response rate $38 \%$; table $1 \mathrm{~A}$ and $\mathrm{B}$ ). Ninety-two $(80 \%)$ were female and $23(20 \%)$ male (59 not reported gender). One hundred five trainees $(60.3 \%)$
Table 1B Specialty of attrition: responders $(n=174)$ vs nonresponders $(n=286)$

\begin{tabular}{lcc}
\hline Specialty & Responders (\%) & $\begin{array}{l}\text { Non- } \\
\text { responders* (\%) }\end{array}$ \\
\hline Anaesthesiology & $3(1.7)$ & $15(5.2)$ \\
Emergency medicine & $4(2.3)$ & $8(2.8)$ \\
$\begin{array}{l}\text { Obstetrics and } \\
\text { gynaecology }\end{array}$ & $5(2.9)$ & $2(0.7)$ \\
Ophthalmology & $1(0.6)$ & $4(1.4)$ \\
$\begin{array}{l}\text { Paediatrics and child } \\
\text { health }\end{array}$ & $4(2.3)$ & $2(0.7)$ \\
Pathology & $7(4.0)$ & $15(5.2)$ \\
$\begin{array}{l}\text { Physicians } \\
\text { (medicine) } \dagger\end{array}$ & $83(47.7)$ & $131(45.8)$ \\
Psychiatry & $16(9.2)$ & $45(15.7)$ \\
Radiology & $15(8.6)$ & $24(8.4)$ \\
\hline Surgery $\ddagger$ & $36(20.7)$ & $40(14.0)$ \\
\hline Total & $174(100)$ & $286(100)$ \\
\hline
\end{tabular}

*Data from non-responders were calculated by subtracting numbers from our sample from the total reference group. Data on the reference group were obtained from the Registration Committee of Medical Specialties.

†Medical specialties include trainees from: cardiology, clinical genetics, dermatology, gastroenterology, general internal medicine, geriatric medicine, hospital medicine, nuclear medicine, neurology, rehabilitation medicine, respiratory medicine, rheumatology, sport and exercise medicine, tropical medicine.

$\ddagger$ Surgical specialties include trainees from: cardiothoracic surgery, general surgery, neurosurgery, orthopaedic surgery, otolaryngology, plastic surgery and urology.

had worked as a DNIT prior to admission as trainee in the same specialty. One hundred thirty-three $(76.4 \%)$ trainees discontinued their training in the first three training years, while almost a quarter $(23.6 \%)$ left in the fourth, fifth or sixth training year. One hundred fortyfour $(82.8 \%)$ trainees decided to discontinue training themselves, sometimes it was a joint decision by both trainee and TPD $(12.6 \%)$ and in $4.6 \%$ of the cases the TPD decided (involuntary attrition).

\section{Factors involved in attrition}

The most frequently mentioned factor involved in attrition was a 'disturbed work-life balance' $(\mathrm{n}=118,67.4 \%)$, followed by 'job content other than expected' ( $\mathrm{n}=77$, $44.0 \%)$, 'workload too heavy' ( $\mathrm{n}=67,38.3 \%)$, 'specialty culture unappealing' $(\mathrm{n}=62,35.4 \%)$ and 'choice to switch specialty' ( $\mathrm{n}=53,30.3 \%)$ (table 2). 'Underperformance without possibilities to improve' was mentioned in 14 cases $(8.0 \%)$.

\section{'Other factors' involved in attrition}

Qualitative analysis of the narrative data revealed three additional factors not provided in the preset list: (1) personal attributes: perfectionism and inability to detach from work, (2) the hospital culture and academic culture: 


\begin{tabular}{|c|c|c|}
\hline Factor: $\mathrm{n}$ times mentioned $(\%)^{*}$ & Total & Ranking \\
\hline Disturbed work-life balance & $118(67.4 \%)$ & 1 \\
\hline Job content other than expected & 77 (44.0\%) & 2 \\
\hline Workload too heavy & $67(38.3 \%)$ & 3 \\
\hline Specialty culture unappealing & $62(35.4 \%)$ & 4 \\
\hline Choice to switch specialty & $53(30.3 \%)$ & 5 \\
\hline Lacking sense of control over job & $49(28.0 \%)$ & 6 \\
\hline Poor career perspective & $29(16.6 \%)$ & 7 \\
\hline Insecure about own capacity & $25(14.4 \%)$ & 8 \\
\hline Personal reasons (disease, family) & $18(10.3 \%)$ & 9 \\
\hline $\begin{array}{l}\text { Better career perspective } \\
\text { elsewhere }\end{array}$ & $17(9.7 \%)$ & 10 \\
\hline Unsafe learning climate & $15(8.6 \%)$ & 11 \\
\hline $\begin{array}{l}\text { Underperformance without } \\
\text { possibilities to improve }\end{array}$ & $14(8.0 \%)$ & 12 \\
\hline Unstimulating learning climate & $13(7.4 \%)$ & 13 \\
\hline Conflict of opinion with supervisors & $12(6.9 \%)$ & 14 \\
\hline Not possible to work part-time & $10(5.7 \%)$ & 15 \\
\hline $\begin{array}{l}\text { Insufficient opportunities for } \\
\text { professional development }\end{array}$ & $7(4.0 \%)$ & 16 \\
\hline Experience of critical incident & $4(2.3 \%)$ & 17 \\
\hline Emigration & $4(2.3 \%)$ & 18 \\
\hline Disciplinary procedure & $1(0.6 \%)$ & 19 \\
\hline \multicolumn{3}{|l|}{ Other factors: $†$} \\
\hline \multicolumn{3}{|l|}{ Personal attributes } \\
\hline \multicolumn{3}{|l|}{$\begin{array}{l}\text { (Academic) hospital culture } \\
\text { unappealing }\end{array}$} \\
\hline $\begin{array}{l}\text { Poor relationship with Training } \\
\text { Programme Director }\end{array}$ & & \\
\hline
\end{tabular}

${ }^{*}$ Respondents mentioned more than one factor involved in leaving their training so percentages add up to $>100$. All factors ranked 1 through 19 were predetermined by studying the three sources as described in the 'Methods' section. These could be selected by the trainees to have played a role or not in their decision to leave. †Other factors were identified from narratives, not categorisable under the preset factors.

authoritarian, impersonal and unsatisfactory communication and (3) poor relationship with TPD, lack of support and commitment, little appreciation as a person and being treated as a 'workhorse'.

\section{Subgroup analysis}

Subgroup analysis revealed no significant gender differences in factors involved in attrition. Comparison of trainees from surgical, medical and other specialities showed that surgical trainees more frequently reported 'poor career perspective' (36\% vs $12 \%$ vs $11 \%, \mathrm{p}=0.002$ ), 'better career perspective elsewhere' (19\% vs $10 \%$ vs $4 \%, \mathrm{p}=0.046)$ and 'insecure about own capacity' $(25 \%$ vs $8 \%$ vs $16 \%, \mathrm{p}=0.049$ ), while trainees from other
Table 3 Future career plans of residents who discontinued training $(n=172)$

\begin{tabular}{lc}
\hline Future employment & n (\%) \\
\hline Switch to other specialty training programme & $114(66.3)$ \\
\hline No specific plans yet & $23(13.4)$ \\
Non-clinical job* & $20(11.6)$ \\
Other position as a doctor† & $13(7.6)$ \\
$\begin{array}{l}\text { Switch to other topographic region (same } \\
\text { specialty) }\end{array}$ & $2(1.2)$ \\
\hline
\end{tabular}

*Positions included: non-clinical medical educator, manager, consultant, researcher, position within pharmaceutical industry, medical illustrator, psychotherapist, master student neurosciences and radiodiagnostic laboratory worker.

†Positions included: doctor not-in-training, cosmetic medicine, fertility medicine and doctor at a secondment agency.

specialties less frequently reported 'choice to switch specialty' ( $33 \%$ vs $39 \%$ vs $17 \%, \mathrm{p}=0.02$ ). Trainees who had worked as a DNIT in the same specialty mentioned 'work content other than expected' less frequently than trainees without prior DNIT employment: $38 \%(40 / 105)$ vs $54 \%(37 / 69)(\mathrm{p}=0.044)$. Trainees leaving in the last three training years reported more often than those who left in the first three training years: 'specialty culture unappealing ' $((\mathrm{n}=20 / 41,49 \%)$ vs $32 \% \quad(42 / 133)$, $\mathrm{p}=0.044)$, 'poor career perspective' $(37 \%(15 / 41)$ vs $11 \%(14 / 133), \mathrm{p}<0.001)$ and 'conflict of opinion with supervisors' $(17 \%(7 / 41)$ vs $4 \%(5 / 132), \mathrm{p}<0.003)$. Trainees older than average more frequently mentioned 'conflict of opinion with supervisors' (14\% (4/29) vs $0 \%$ $(0 / 39), \mathrm{p}=0.03)$.

\section{Future career plans}

The majority continued their career as a clinical doctor $(\mathrm{n}=129,75 \%)$. Most trainees decided to switch to another training programme $(\mathrm{n}=114 / 172,66.3 \%)$. Twenty trainees $(11.6 \%)$ reported continuing their career in a non-clinical role, $13(7.6 \%)$ obtained another position as a doctor (table 3 ).

Of the trainees who switched specialty, 39 (35.2\%) continued their career in another hospital-based specialty, $72(64.8 \%)$ chose a non-hospital-based specialty of whom over a third in general practice $(n=42,37.8 \%)$, followed by public health $(\mathrm{n}=21,18.9 \%)$ and occupational health $(n=9,8.1 \%)$ (figure 1 and table 4$)$. Table 4 shows the relationship between the specialty of origin and the specialty switched to. All trainees switching to surgery originated from surgical specialties. Most of the trainees switching to medicine and other specialties originated from medicine and other specialties, respectively.

\section{Subgroup analysis}

Future career plans in relation to gender, age, training year or specialty showed no differences. 


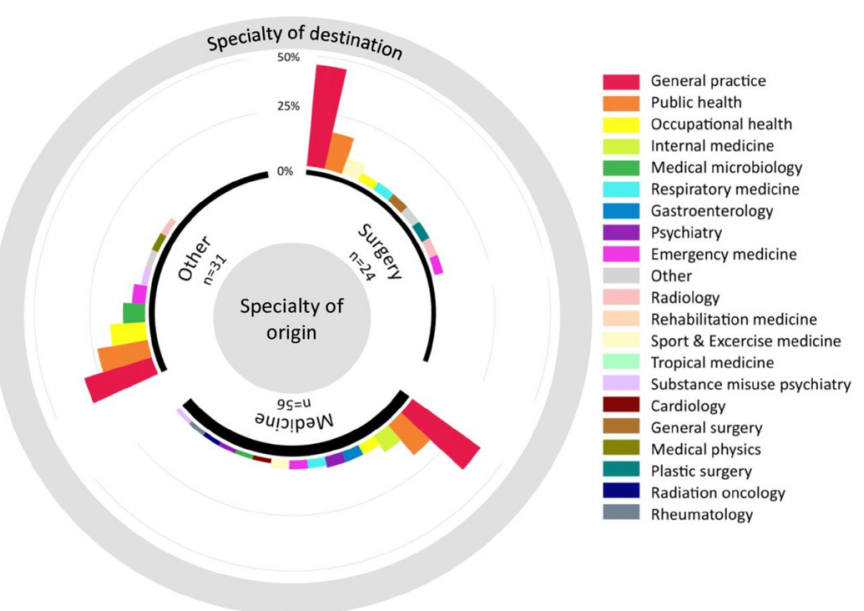

Figure 1 Relationship between specialty of origin and specialty of destination.

\section{DISCUSSION}

We conducted a nationwide survey study among trainees who prematurely left hospital-based specialty training in order to provide insight into the factors involved in attrition and in future career paths. The most frequently mentioned factors were work-life balance, job content, workload and specialty culture. The majority of the trainees continued to work as a medical doctor, of whom two-thirds switched to a non-hospital context.

Both medical and surgical trainees frequently mentioned the importance of work-life balance, while the latter are often ascribed to have less controllable lifestyles. $^{28912}$ Current generations of trainees experience 'the unanticipated toll on their personal life ${ }^{16}$ differently than former generations, where a 'resident's life outside the hospital was simply not a priority'. ${ }^{30}$ We consider the frequently mentioned disturbed work-life balance in our study of major concern given the association of a poor work-life balance with personal burn-out, an impaired safety climate ${ }^{31}$ and in relation to the high burn-out rates in residency. ${ }^{32}$ Therefore, focusing on work-life balance as part of physician well-being is pivotal for a sustainable healthcare system. ${ }^{33-35}$ Administrative demands are a growing burden to the current medical workforce in general. ${ }^{3436}$ Trainees in our study noted that not only the daily clinical workload, but also the administrative burden and ancillary activities, for example, keeping training portfolio up to date, contributed unevenly to the overall workload. Attempts to solve this problem include redesigning policy and regulations at community level. ${ }^{33} 35$

Over $60 \%$ of our respondents dropped-out despite their prior experience as a DNIT in the same specialty. We expected that DNIT year(s) would help future trainees to recognise the demands of specialty training and thus prevent attrition, as also suggested by Khoushhal et al. ${ }^{8}$

Another prominent observation from our study is the major switch $(64.8 \%)$ from hospital to non-hospital specialties training programmes. This finding is in line with a large cohort study investigating career choices, ${ }^{37}$ which shows that only half of all doctors working in general practice had chosen this specialty in their early career. Our study does not provide insight into the reasons for the switch to the non-hospital context. Follow-up studies may reveal whether trainees actually experience a better fit with work-life balance, job content and specialty culture.

Our study supports earlier findings that attrition most often occurs in the first 2-3 years ${ }^{9}$ of training. ${ }^{12}$ We found, however, a high number $(25 \%)$ of 'late leavers', that is, in year 4,5 or 6 . Apparently, it takes time to realise the mismatch between trainee and specialty programme.

We deem it important to emphasise that attrition is not always avoidable or negative. First, although some scholars advocate the importance of early career mentorship creating realistic expectations, ${ }^{18} 38$ others have shown that career perspectives and priorities change over time as life progresses. ${ }^{39}$ Trainees may face unanticipated problems, for example, illness or loss of a loved one, whereas the impact of other life events such as raising a family requires them to reprioritise roles. ${ }^{39}$ Therefore, while some pretraining preparation is helpful, providing access to guidance and support promoting career adaptability is also important during training. ${ }^{40} 41$ Second, some of the leaving trainees may have developed more self-awareness regarding strengths and weaknesses, resulting in

Table 4 Relationship between specialty of origin and specialty switched to

Specialty switched to

\begin{tabular}{llcccll} 
& & & & & \multicolumn{2}{l}{ Occupational } \\
Specialty of origin & Surgery & Medicine & Other $^{*}$ & Public health & health & General practice \\
\hline Surgery $(n=24)$ & $\mathbf{2 ( 8 . 3 \% )}$ & $3(12.5 \%)$ & $3(12.5 \%)$ & $4(16.7 \%)$ & $1(4.2 \%)$ & $11(45.8 \%)$ \\
Medicine $(n=56)$ & 0 & $\mathbf{1 6}(\mathbf{2 8 . 6 \% )}$ & $6(9.1 \%)$ & $10(17.9 \%)$ & $3(5.4 \%)$ & $21(37.5 \%)$ \\
Other $(n=31)^{*}$ & 0 & 0 & $\mathbf{9 ( 2 9 . 0 \% )}$ & $7(22.6 \%)$ & $5(16.1 \%)$ & $10(32.3 \%)$ \\
Total $(n=111)$ & $2(1.8 \%)$ & $19(17.1 \%)$ & $18(16.2 \%)$ & $21(18.9 \%)$ & $9(8.1 \%)$ & $42(37.8 \%)$ \\
\hline
\end{tabular}

$\mathrm{X}^{2}, \mathrm{p}<0.004$.

*Other hospital-based specialties included: anaesthesiology, emergency medicine, ophthalmology, obstetrics and gynaecology, paediatrics, pathology, psychiatry and radiology.

Bold values signifies that all trainees switching to surgical specialties originated from surgery; and that most trainees switching to medical or other specialties originated from medical and other specialties resp. 


\section{Box 1 Implications for practice at three levels}

\section{Individual trainee \\ 1. Before training \\ - Engage in a reality check regarding work-life balance, job con- tent and culture of the specialty before actually pursuing a train- ee position.}

2. During training

- Acknowledge importance of and allocate time for regular and critical reflection on job content, culture and work-life balance.

\section{Specialty training programme}

1. Before training (doctor not-in-training, trainee selection)

- Arrange reality check sessions for applicants, especially on work-life balance, content and culture and training demands. Incorporate these factors into selection procedures.

2. During training

- Create dedicated time and easy access to career support, such as coaching and mentoring, for all trainees.

- Provide regular feedback to assure and reassure fit with specialty, and be open about doubts.

- Encourage role models to show that regular reflection on fit with specialty and work-life balance is beneficial to all.

\section{Governmental institutions and policymakers}

1. Acknowledge the importance of a healthy workforce as societal issue and advocate policies that enhance a good work-life balance. This should allow physicians to combine career demands with other roles and priorities in life.

2. Adapt regulations to facilitate switching to another specialty and allow programmes to replace a trainee.

the choice for a better fitting specialty. From a societal perspective, the finding that a large proportion of leaving trainees pursues a career in general practice may be a better fit for the individual and is in line with transitions in healthcare from hospital to non-hospital care settings.

In general, stakeholders at all levels, that is, trainee, programme, workforce, will benefit if a potential mismatch between trainee and specialty is timely identified and resolved. We suggest a number of interventions to limit avoidable attrition (box 1).

Although attrition is not always a negative outcome, the reported attrition rates may only be the tip of the iceberg. Several publications report a substantial proportion of trainees seriously considering leaving training. ${ }^{42}$ Future studies might explore whether doubt is worrisome, possibly indicating unhappiness with the chosen specialty, normal or even desirable, indicating a reflective attitude.

Our study provides valuable insight into the factors involved in attrition. However, how trainees actually perceived and valued the preset factors, how different factors inter-relate and which events take place during the decision-making process leading to the final decision to leave has to be elucidated in future studies. In addition, the proportion of and reasons for (newly qualified) consultants to leave practice need further study. ${ }^{445}$ Future work also needs to focus on attrition at different moments in the educational continuum: what distinguishes doctors who leave early from those who leave in later stages?
Using the approach of safety-II-thinking, focus on why the majority of trainees successfully completes specialty training will be valuable.

The strength of our study is the insight it provides in nationwide factors involved in attrition from all hospital-based medical training programmes over an extended period, reported by the trainees involved. Moreover, we obtained an overview of subsequent career ambitions of leaving trainees.

A first limitation of our study is the response rate. The survey was anonymous and therefore it was impossible to send reminders, disabling responder versus non-responder comparisons. It remains unknown how non-response bias may have affected our results. However, limited information on the reference group, the total group of leaving trainees during our study period, shows that our sample is representative for age and specialty. A second limitation is that we do not know if and how the proportion of women in our sample, which was slightly larger than in the reference population, might have affected our findings. However, subgroup analyses showed no differences in factors involved in attrition between male and female trainees.

A third limitation lies in the fact that our data are based on trainees' perceptions and reflections on personal experiences. Respondents may have interpreted and valued preset factors differently. Furthermore, studies have shown that when people look back on experiences, they give new meaning to the initial experiences. Using a preset list of factors might have influenced this process too. Given the potential psychological effects like internal and external attribution ${ }^{46}$ and cognitive dissonance, ${ }^{47}$ results should be interpreted with this in mind.

\section{CONCLUSIONS}

Our study shows that work-life balance, job content and specialty culture are the three most frequently mentioned reasons for attrition. Most trainees switch specialty, the majority towards non-hospital-based specialties. These findings underline the importance of preparing the future generation doctors with realistic expectations on what it takes to be a trainee in a specific hospital-based specialty. Regular reflection on characteristics of the specialty of choice could be helpful before obtaining a training position, in the recruitment processes and during training. Fostering trainees' career development by introducing career support programmes and developing signalling strategies for trainees in doubt can also be valuable. Overall, mitigation of attrition requires a proactive approach and targeted interventions at the level of individual trainees, specialty training programmes and society.

\section{Author affiliations}

${ }^{1}$ Centre for Innovation in Medical Education, Leiden University Medical Centre, Leiden, The Netherlands

${ }^{2}$ Department of Obstetrics, Leiden University Medical Center, Leiden, The Netherlands 
${ }^{3}$ Department of Pathology, RadboudUMC, Nijmegen, The Netherlands ${ }^{4}$ Department of Education Development and Research, Maastricht University, Maastricht, The Netherlands

Acknowledgements The authors would like to thank Joep Dörr (†), Lenneke Weijts, Wilco Doeser, Friedo Dekker, Anne van Leeuwen-Nipshagen, Hayley Allan and Carlijn van de Water for their valuable contribution to the study.

Contributors JB and KD contributed equally to this work. JB, SV and AJdB were responsible for the initial study design, securing funding for the study and the overall monitoring of the study. RvdP joined them in drafting the original study proposal and the design of the survey. $\mathrm{KD}$ contributed to the refinement of the study design and performed data analyses. JB, KD and AJdB were responsible for data interpretation, drafted the manuscript and revised the manuscript before submission. ED, RvdP and JMMvL provided critical feedback on the study design, conduct and reporting of the study at several stages during the study period. All authors contributed to and approved the final manuscript. The corresponding author attests that all listed authors meet authorship criteria and that no others meeting the criteria have been omitted.

Funding This study was funded by the Dutch Ministry of Health, Welfare and Sport (grant number 322032).

Competing interests None declared.

Patient consent for publication Not required.

Ethics approval This study was approved by the Ethical Review Board of Leiden University Medical Centre (reference number C17.061).

Provenance and peer review Not commissioned; externally peer reviewed.

Data sharing statement Extra data and the survey used in this study are available by emailing the corresponding author (K.Dijkhuizen@lumc.nl).

Open access This is an open access article distributed in accordance with the Creative Commons Attribution Non Commercial (CC BY-NC 4.0) license, which permits others to distribute, remix, adapt, build upon this work non-commercially, and license their derivative works on different terms, provided the original work is properly cited, appropriate credit is given, any changes made indicated, and the use is non-commercial. See: http://creativecommons.org/licenses/by-nc/4.0/.

\section{REFERENCES}

1. Bongiovanni T, Yeo $\mathrm{H}$, Sosa JA, et al. Attrition from surgical residency training: perspectives from those who left. Am J Surg 2015;210:648-54.

2. Ginther DN, Dattani S, Miller S, et al. Thoughts of quitting general surgery residency: factors in Canada. J Surg Educ 2016;73:513-7.

3. Schwed AC, Lee SL, Salcedo ES, et al. Association of general surgery resident remediation and program director attitudes with resident attrition. JAMA Surg 2017;152:1134-40.

4. Renfrow JJ, Rodriguez A, Liu A, et al. Positive trends in neurosurgery enrollment and attrition: analysis of the 2000-2009 female neurosurgery resident cohort. J Neurosurg 2016;124:834-9.

5. Bauer JM, Holt GE. National orthopedic residency attrition: who is at risk? J Surg Educ 2016;73:852-7.

6. Badran KW, Kelley K, Conderman C, et al. Improving applicant selection: identifying qualities of the unsuccessful otolaryngology resident. Laryngoscope 2015;125:842-7.

7. Shaw C, Sarosi GA. Reducing Surgical Resident Attrition. JAMA Surg 2018;153:717.

8. Khoushhal Z, Hussain MA, Greco E, et al. Prevalence and causes of attrition among surgical residents: a systematic review and metaanalysis. JAMA Surg 2017;152:265-72.

9. Shweikeh $\mathrm{F}$, Schwed $\mathrm{AC}, \mathrm{Hsu} \mathrm{CH}$, et al. Status of resident attrition from surgical residency in the past, present, and future outlook. $J$ Surg Educ 2018;75:254-62.

10. Contessa J, Suarez L, Kyriakides T, et al. The influence of surgeon personality factors on risk tolerance: a pilot study. J Surg Educ 2013;70:806-12.

11. Lin $\mathrm{H}$, Lin $\mathrm{E}$, Auditore $\mathrm{S}$, et al. A narrative review of high-quality literature on the effects of resident duty hours reforms. Acad Med 2016:91:140-50.

12. Morris JB, Leibrandt TJ, Rhodes RS. Voluntary changes in surgery career paths: a survey of the program directors in surgery. J Am Coll Surg 2003;196:611-6.

13. Leibrandt TJ, Pezzi CM, Fassler SA, et al. Has the 80-hour work week had an impact on voluntary attrition in general surgery residency programs? J Am Coll Surg 2006;202:340-4.
14. Resnick AS, Mullen JL, Kaiser LR, et al. Patterns and predictions of resident misbehavior--a 10-year retrospective look. Curr Surg 2006;63:418-25.

15. Naylor RA, Reisch JS, Valentine RJ. Factors related to attrition in surgery residency based on application data. Arch Surg 2008;143:647-52.

16. Sullivan $\mathrm{MC}$, Yeo $\mathrm{H}$, Roman $\mathrm{SA}$, et al. Surgical residency and attrition: defining the individual and programmatic factors predictive of trainee losses. J Am Coll Surg 2013;216:461-71.

17. Dodge R, Daly A, Huyton J, et al. The challenge of defining wellbeing. International Journal of Wellbeing 2012;2:222-35.

18. Querido SJ, Vergouw D, Wigersma L, et al. Dynamics of career choice among students in undergraduate medical courses. A BEME systematic review: BEME Guide No. 33. Med Teach 2016;38:18-29.

19. Haydarov R, Moxley V, Anderson D. Counting chickens before they are hatched: an examination of student retention, graduation, attrition, and dropout measurement validity in an online master's environment. Journal of College Student Retention: Research, Theory \& Practice 2013;14:429-49.

20. Castro Lopes S, Guerra-Arias M, Buchan J, et al. A rapid review of the rate of attrition from the health workforce. Hum Resour Health 2017;15:21.

21. Gruppen LD, Stansfield RB, Zhao Z, et al. Institution and specialty contribute to resident satisfaction with their learning environment and workload. Acad Med 2015;90(11 Suppl):S77-82.

22. Stroud L, Bryden P, Kurabi B, et al. Putting performance in context: the perceived influence of environmental factors on work-based performance. Perspect Med Educ 2015;4:233-43.

23. Manriquez Gilpin M, Gilpin MM. Residency attrition rate in obstetrics and gynecology: are we losing more postgraduates today? Am J Obstet Gynecol 2005;193:1804-6.

24. Scheele F, Van Luijk S, Mulder $\mathrm{H}$, et al. Is the modernisation of postgraduate medical training in the Netherlands successful? Views of the NVMO Special Interest Group on Postgraduate Medical Education. Med Teach 2014;36:116-20.

25. LFJvd V, Hingstman L. Het medisch opleidingstraject: waar blijft de (leef)tijd? 2003:1-80.

26. Weggemans MM, van Dijk B, van Dooijeweert $B$, et al. The postgraduate medical education pathway: an international comparison. GMS J Med Educ 2017;34.

27. Capaciteitsorgaan. Capaciteitsplan 2016 - Deelrapport 1. 2016

28. Demerouti E, Bakker AB, Nachreiner F, et al. The job demandsresources model of burnout. J Appl Psychol 2001;86:499-512.

29. NHS. NHS specialties. https://www.bma.org.uk/advice/career/ studying-medicine/insiders-guide-to-medical-specialties/nhs-careerchoices.

30. Birkmeyer JD. Surgical Resident Duty-Hour Rules--Weighing the New Evidence. N Engl J Med 2016;374:783-4.

31. Schwartz SP, Adair KC, Bae J, et al. Work-life balance behaviours cluster in work settings and relate to burnout and safety culture: a cross-sectional survey analysis. BMJ Qual Saf 2019;28:bmjqs-2018-007933.

32. Holmes EG, Connolly A, Putnam KT, et al. Taking care of our own: a multispecialty study of resident and program director perspectives on contributors to burnout and potential interventions. Acad Psychiatry 2017;41:159-66.

33. Thomas LR, Ripp JA, West CP. Charter on Physician Well-being. JAMA 2018;319:1541-2.

34. Wallace JE, Lemaire JB, Ghali WA. Physician wellness: a missing quality indicator. Lancet 2009;374:1714-21.

35. West CP, Dyrbye LN, Erwin PJ, et al. Interventions to prevent and reduce physician burnout: a systematic review and meta-analysis. Lancet 2016;388:2272-81.

36. Woolhandler S, Himmelstein DU. Administrative work consumes one-sixth of U.S. physicians' working hours and lowers their career satisfaction. Int J Health Serv 2014;44:635-42.

37. Goldacre MJ, Laxton L, Lambert TW. Medical graduates' early career choices of specialty and their eventual specialty destinations: UK prospective cohort studies. BMJ 2010;341:c3199.

38. Abelson JS, Sosa JA, Symer MM, et al. Association of expectations of training with attrition in general surgery residents. JAMA Surg 2018;153:712-7.

39. Isaac C, Byars-Winston A, McSorley R, et al. A qualitative study of work-life choices in academic internal medicine. Adv Health Sci Educ Theory Pract 2014;19:29-41.

40. O'Brien BC. What to do about the transition to residency? Exploring problems and solutions from three perspectives. Acad Med 2018;93:681-4

41. Rudolph CW, Lavigne KN, Zacher H. Career adaptability: a metaanalysis of relationships with measures of adaptivity, adapting responses, and adaptation results. J Vocat Behav 2017;98:17-34 
42. van den Heijkant F, Tomlow B, Prins J, et al. Minder aiossen burnout, maar actie blijft nodig. Medisch Contact 2016;17/18:18-21.

43. Adams S, Ginther DN, Neuls E, et al. Attitudes and factors contributing to attrition in Canadian surgical specialty residency programs. Can J Surg 2017;60:247-52.

44. Degen C, Weigl M, Glaser J, et al. The impact of training and working conditions on junior doctors' intention to leave clinical practice. BMC Med Educ 2014;14:119.
45. Pantenburg B, Luppa $\mathrm{M}$, König $\mathrm{HH}$, et al. Burnout among young physicians and its association with physicians' wishes to leave: results of a survey in Saxony, Germany. J Occup Med Toxicol 2016;11:2.

46. Heider F. The psychology of interpersonal relations: Psychology Press, 2013.

47. Festinger L. A theory of cognitive dissonance: Stanford university press, 1962. 